\title{
Respiratory Protective Equipment Reconsiderations in the Age of SARS-CoV-2
}

Aerosol and Air Quality Research

\author{
Wei-Ren $\mathrm{Ke}^{1}$, Chih-Chieh Chen², Sheng-Hsiu Huang ${ }^{2 *}$ \\ ${ }^{1}$ School of Pharmacy, College of Medicine, National Taiwan University, Taipei 100, Taiwan \\ ${ }^{2}$ Institute of Environmental and Occupational Health Sciences, College of Public Health, \\ National Taiwan University, Taipei 100, Taiwan
}

\section{ABSTRACT}

The use of respiratory protective equipment (RPE) has been recognized as an effective measure to mitigate droplet and airborne transmission of SARS-CoV-2. Although there are various types of RPE available, different RPEs serve different purposes and offer various levels of protection against aerosols. Additionally, recent evidence highlights the role of good fit in ensuring the effectiveness of RPEs. Some modified procedures can enhance the effectiveness of surgical masks by improving fit. In the age of SARS-CoV-2, there is an urgent need for knowledge about RPEs. The correct selection and use of RPEs are of pivotal importance for breaking the transmission chain of SARS-CoV-2.

Keywords: SARS-CoV-2, Respiratory protective equipment, Surgical mask, Filtering facepiece respirator, Powered air-purifying respirator

\section{MAIN TEXT}

The ongoing SARS-CoV-2 pandemic has paralyzed both the global economy and the health care system since December 2019. Several vaccines have been developed and distributed to stop the virus transmission and reach herd immunity. However, due to the emergence of highly contagious SARS-CoV-2 variants, such as Delta and Omicron variants of concern (VOCs; formerly known as B.1.617.2 and B. 1.1. 529, respectively), and vaccine shortage, this global pandemic still poses a growing threat to public health. The donor-to-recipient transmission of SARS-CoV-2 is highly complex and has multiple pathways. Recent converging evidence has shown that SARS-CoV-2 is predominantly transmitted via non-contact transmission modes, including droplet and airborne transmissions (Greenhalgh et al., 2021; Leung, 2021). These non-contact transmission modes are forms of respiratory transmission via exposure to pathogen-laden respiratory fluids in the form of aerosols (Hsiao et al., 2020). Various human airway activities can produce respiratory aerosols across a range of sizes. Violent expiratory activities, including coughing, sneezing, and speaking, generally produce large droplets (tens to hundreds of $\mu \mathrm{m}$ ) (Bourouiba et al., 2014; Asadi et al., 2019), while tidal breathing leads to the production of aerosols from a few microns to submicron in size (Scheuch, 2020). After aerosolization, SARS-CoV-2 can float in the air and remain viable for an extended period (1.5-16 hours), depending on the ambient conditions and physical properties of aerosols (Fears et al., 2020; Smither et al., 2020; van Doremalen et al., 2020). Moreover, Delta and Omicron VOCs has been associated with higher viral loads when compared to the original SARS-CoV-2 strain (Teyssou et al., 2021; Peacock et al., 2022). This property could contribute to the higher probability of the generation of smaller virus-laden aerosols, further increasing the risk of non-contact transmission (Lee, 2020, 2021). Riediker et al. (2022) estimated the viral emissions with different VOCs in the fine aerosols using a Monte Carlo modelling approach. Their results show that Delta and Omicron VOCs cause a strong (ca. 30-50 times) increase in the frequency of super-emitters in population when comparing the original strain (Riedikera et al., 2022). To avoid exposure to infectious aerosols, several intervention measures, including improving ventilation and 
air filtration, social distancing, and the use of respiratory protective equipment (RPE), have been widely implemented during this pandemic.

Although the effectiveness of the RPE usage against SARS-CoV-2 was initially controversial, continuous updates have revealed that RPE plays a pivotal role in mitigating the pandemic (Martinelli et al., 2021; Rahimi et al., 2021). Thus, many countries have already recommended or mandated the use of RPEs in public. This also causes unprecedented demands (and shortages) for RPEs. There are multiple types of RPEs available. Depending on the type, RPE can be used either to protect healthy persons or to prevent onward transmission. However, the incorrect selection and use of RPEs may give people a false sense of security, reducing compliance with other intervention measures. Therefore, knowledge about specific characteristics of RPEs is of utmost importance to correctly use and select the proper type.

Surgical masks, loose-fitting and disposable devices, are the most-used type of RPEs in public during the pandemic (Feng et al., 2020). They are intended to reduce the emission and inhalation of large droplets by creating a physical barrier (Kähler and Hain, 2020). On the contrary, these masks are not designed to protect against airborne particles (Oberg and Brosseau, 2008). Although the filter media of surgical masks, to some extent, enables to collect airborne particles (filtration efficiency for $0.3 \mu \mathrm{m}$ particles at an airflow of $95 \mathrm{~L} \mathrm{~min}^{-1}: 28.4-85.5 \%$ ) (Kulmala et al., 2021), such particles tend to slip through or escape from gaps between the mask and the facial contours instead of being filtered through the mask itself (Chen and Willeke, 1992; Cappa et al., 2021; Su et al., 2022). Therefore, the effectiveness of these masks in reducing airborne particle exposure is limited and varies between individuals, mainly depending on how well the fit of the "loosefitting" surgical mask is. Milton et al. (2013) examined the effect of wearing surgical masks on the reduction of influenza aerosol transmission. Their results demonstrated that surgical masks reduced viral emission by 25 -fold in the coarse aerosols $(>5 \mu \mathrm{m})$ and by 2.8 -fold in the fine aerosols $(\leq 5 \mu \mathrm{m})$ (Milton et al., 2013). According to a CDC (Centers for Disease Control and Prevention, US) updated guidance, two methods can overcome this issue (CDC, 2021). One is wearing a cloth mask or using a mask fitter over a surgical mask; the other is knotting the ear loops and tucking in the side pleats. Recent laboratory-based experiments have shown that both methods could substantially reduce the risk of exposure to airborne particles when compared to the regular-used surgical mask alone (Mueller et al., 2020; Clapp et al., 2021; Sankhyan et al., 2021). In the study by Rothamer et al. (2021), a comparison between the surgical mask alone and the surgical mask with a mask fitter was explored. The overall filtration efficiency significantly increased from $44.7 \%$ to $93.9 \%$ when the mask fitter was used (Rothamer et al., 2021). Another study observed that knotting the ear loops and tucking in the side pleats of the surgical masks cause a significant improvement in the overall filtration efficiency $(60.3 \%)$ when compared to the regular-used surgical masks (38.5\%) (Clapp et al., 2021). The principle of these methods is to improve the mask fit and prevent air from leaking in and out around the edges of surgical masks. This also highlights the importance of a good fit to maximize the effectiveness of masks (Pan et al., 2020).

Filtering facepieces respirators (FFRs, e.g., N95/FFP2, N99/FFP3) are tight-fitting and disposable devices with high filtration efficiency. In contrast with surgical masks, they are intended to provide respiratory protection. The filter media of NIOSH (National Institute for Occupational Safety and Health)-approved N95 respirators, for instance, is capable of filtering at least $95 \%$ of aerosols in the count median diameter of $0.075 \mu \mathrm{m}$ at a high flow rate of $85 \mathrm{~L} \mathrm{~min}^{-1}$ (NIOSH, 2019). As a result, their filtration efficiencies at tidal breathing conditions (lower flow rates) are expected to be higher than the tested ones (Huang et al., 2013). Zhou and Cheng (2017) also investigated the filtration efficiency of the N95 FFR using the challenge aerosol of titanium dioxide at flow rates of $30,85,130 \mathrm{~L} \mathrm{~min}^{-1}$. Their results showed that the minimum filtration efficiency increased from around $93 \%$ to over $99 \%$, with decreasing flow rate from 130 to $30 \mathrm{~L} \mathrm{~min}^{-1}$ (Zhou and Cheng, 2017). However, FFRs can provide the claimed effectiveness for the wearer only when FFR performs a tight seal on the wearer's face (Ardon-Dryer et al., 2021). The presence of leaks, even for small leaks, will lead to unfiltered air drawn inside the FFR and drastically compromise the effectiveness of the FFR (Noti et al., 2012; Ippolito et al., 2020). Chen et al. (1990) examined the effect of the face seal leakage in the FFR (disposable dust/mist respirator) on the aerosol penetration. A small tube of $4 \mathrm{~mm}$ diameter was added to the FFR to mimic the face seal leak. With increasing leak hole size from 0 to $4 \mathrm{~mm}$ at the flow rate of $32 \mathrm{~L} \mathrm{~min}^{-1}$, the penetrations of 1 - and 4 - $\mu \mathrm{m}$ aerosol 
particles increased ca. 6 and 10\%, respectively (Chen et al., 1990). Thus, the wearer must find the best fitting model and size of FFRs. To ensure that FFR can provide adequate airborne protection, fit testing is required per OSHA (Occupational Safety and Health Administration, US) regulations for the wearer. Fit testing can determine whether a specific FFR obtains an acceptable fit on a specific wearer. However, due to the shortage of FFRs during the pandemic, wearers hardly have an option to choose, not to mention adopting fit testing. This may enhance their risks of acquiring infection when working in a hazardous environment (Fakherpour et al., 2021). Moreover, no modified procedures have been approved for improving the fit of FFR. Unlike the surgical mask, it is not recommended to use FFR with other masks. This is because any difference in breathing resistance may cause unexpected leaks, and additional mask filter media and straps may alter the original fit of FFR (Nelson and Colton, 2000). Thus, CDC guidance does not recommend combining FFR and any other mask (CDC, 2021).

For people who cannot find a proper fit of FFR or has a low tolerance for wearing FFR, a powered air-purifying respirator (PAPR) is an alternative to provide respiratory protection (Licina et al., 2020). Conventional PAPRs consist of a battery-operated blower that forces positive airflow through filters and/or cartridges and into the wearer's breathing zone. These devices can be used for protection against aerosols and various hazardous gases, depending on which filters or cartridges are used. High-efficiency particulate air (HEPA) filter considered as a filter of choice for infection control airborne precautions is generally used in PAPR. As the blower actively introduces filtered air to maintain positive pressure inside the respirator, no fit testing is required for NIOSH-approved PAPRs with loose-fitting headgear (e.g., hoods and helmets) (CDC, 2020). Although PAPRs offer several advantages, they are far clumsier and more expensive than other types of RPEs. Thus, PAPRs are generally used for protection against SARS-CoV-2 in healthcare settings. Recently, wearable air purifiers have been released, referred to as Breath Responsive PAPR (BR-PAPR). This purifier has integrated all components of conventional PAPR into a half-face respirator with an auto-feedback system controlling the blower speed (Zhao et al., 2021). It retains the advantages of PAPR and resolves the issue of clumsiness and expensiveness. The BR-PAPR has a great potential to use for respiratory protection in the future (Chughtai et al., 2020).

There is a continuing debate on the benefits and risks of using FFRs with exhalation valves and PAPRs during the pandemic (Chang et al., 2020; Ippolito et al., 2020). These types of RPEs are originally designed for respiratory protection instead of source control. Thus, although they enable to reduce contamination and exhalation effort substantially, the unfiltered exhaled air from the wearer will directly stream into the environment. Infected individuals should not use these RPEs, as the risks associated with these designs are not intuitive to the general population as well as healthcare practitioners. This may cause an additional and underrecognized transmission source. On the contrary, people who are not suspected of SARS-CoV-2 or recently tested negative may still be suitable to use these RPEs. Although the World Health Organization (WHO) does not advise using an FFR with an exhalation valve during this pandemic (WHO, 2020), there is still a need to use these types RPEs, particularly for healthcare practitioners work long hours at significant risk of contracting SARS-CoV-2.

In the age of SARS-CoV-2, there is an urgent need for knowledge about RPEs. The correct selection and use of RPEs are of pivotal importance for the general population and healthcare practitioners. Recent evidence highlights the role of good fit in ensuring the effectiveness of RPEs. To achieve good fit, fit testing for FFRs is necessary and should be implemented. Lastly, it is also essential for health authorities to reconsider and timely update guidelines for the use and selection of RPEs. This can help increase compliance and break the transmission chain of SARS-CoV- 2 .

\section{REFERENCES}

Ardon-Dryer, K., Warzywoda, J., Tekin, R., Biros, J., Almodovar, S., Weeks, B.L., Hope-Weeks, L.J., Sacco, A., Jr. (2021). Mask material filtration efficiency and mask fitting at the crossroads: Implications during pandemic times. Aerosol Air Qual. Res. 21, 200571. https://doi.org/10.42 09/aaqr.200571

Asadi, S., Wexler, A.S., Cappa, C.D., Barreda, S., Bouvier, N.M., Ristenpart, W.D. (2019). Aerosol emission and superemission during human speech increase with voice loudness. Sci. Rep. 9, 
2348. https://doi.org/10.1038/s41598-019-38808-z

Bourouiba, L., Dehandschoewercker, E., Bush, J.W.M. (2014). Violent expiratory events: On coughing and sneezing. J. Fluid Mech. 745, 537-563. https://doi.org/10.1017/jfm.2014.88

Cappa, C.D., Asadi, S., Barreda, S., Wexler, A.S., Bouvier, N.M., Ristenpart, W.D. (2021). Expiratory aerosol particle escape from surgical masks due to imperfect sealing. Sci. Rep. 11, 12110. https://doi.org/10.1038/s41598-021-91487-7

Centers for Disease Control and Prevention (CDC) (2020). Powered Air Purifying Respirators. https://www.cdc.gov/Coronavirus/2019-Ncov/Hcp/Ppe-Strategy/Powered-Air-PurifyingRespirators-Strategy.Html (accessed 28 December 2021).

Centers for Disease Control and Prevention (CDC) (2021). Improve How Your Mask Protects You. https://www.cdc.gov/coronavirus/2019-ncov/your-health/effective-masks.html (accessed 26 July 2021).

Chang, J.C., Johnson, J.S., Olmsted, R.N. (2020). Demystifying theoretical concerns involving respirators with exhalation valves during COVID-19 pandemic. Am. J. Infect. Control 48, 15641565. https://doi.org/10.1016/j.ajic.2020.08.031

Chen, C.C., Ruuskanen, J., Pilacinski, W., Willeke, K. (1990). Filter and leak penetration characteristics of a dust and mist filtering facepiece. Am. Ind. Hyg. Assoc. J. 51, 632-639. https://doi.org/10.10 80/15298669091370275

Chen, C.C., Willeke, K. (1992). Aerosol penetration through surgical masks. Am. J. Infect. Control 20, 177-184. https://doi.org/10.1016/s0196-6553(05)80143-9

Chughtai, A.A., Seale, H., Rawlinson, W.D., Kunasekaran, M., Macintyre, C.R. (2020). Selection and use of respiratory protection by healthcare workers to protect from infectious diseases in hospital settings. Ann. Work Exposures Health 64, 368-377. https://doi.org/10.1093/annweh/ wxaa020

Clapp, P.W., Sickbert-Bennett, E.E., Samet, J.M., Berntsen, J., Zeman, K.L., Anderson, D.J., Weber, D.J., Bennett, W.D. (2021). Evaluation of cloth masks and modified procedure masks as personal protective equipment for the public during the COVID-19 pandemic. JAMA Intern. Med. 181, 463-469. https://doi.org/10.1001/jamainternmed.2020.8168

Fakherpour, A., Jahangiri, M., Seif, M., Charkhand, H., Abbaspour, S., Floyd, E.L. (2021). Quantitative fit testing of filtering face-piece respirators during the COVID-19 pandemic reveals anthropometric deficits in most respirators available in Iran. J. Environ. Health Sci. Eng. 19, 805817. https://doi.org/10.1007/s40201-021-00648-3

Fears, A.C., Klimstra, W.B., Duprex, P., Hartman, A., Weaver, S.C., Plante, K.S., Mirchandani, D., Plante, J.A., Aguilar, P.V., Fernández, D., Nalca, A., Totura, A., Dyer, D., Kearney, B., Lackemeyer, M., Bohannon, J.K., Johnson, R., Garry, R.F., Reed, D.S., Roy, C.J. (2020). Persistence of severe acute respiratory syndrome coronavirus 2 in aerosol suspensions. Emerg. Infect. Dis. 26, 21682171. https://doi.org/10.3201/eid2609.201806

Feng, S., Shen, C., Xia, N., Song, W., Fan, M., Cowling, B.J. (2020). Rational use of face masks in the COVID-19 pandemic. Lancet Respir. Med. 8, 434-436. https://doi.org/10.1016/S22132600(20)30134-X

Greenhalgh, T., Jimenez, J.L., Prather, K.A., Tufekci, Z., Fisman, D., Schooley, R. (2021). Ten scientific reasons in support of airborne transmission of SARS-CoV-2. Lancet 397, 1603-1605. https://doi.org/10.1016/S0140-6736(21)00869-2

Hsiao, T.C., Chuang, H.C., Griffith, S.M., Chen, S.J., Young, L.H. (2020). COVID-19: An aerosol's point of view from expiration to transmission to viral-mechanism. Aerosol Air Qual. Res. 20, 905-910. https://doi.org/10.4209/aaqr.2020.04.0154

Huang, S.H., Chen, C.W., Kuo, Y., Lai, C.Y., McKay, R., Chen, C.C. (2013). Factors affecting filter penetration and quality factor of particulate respirators. Aerosol Air Qual. Res. 13, 162-171. https://doi.org/10.4209/aaqr.2012.07.0179

Ippolito, M., lozzo, P., Gregoretti, C., Grasselli, G., Cortegiani, A. (2020). Facepiece filtering respirators with exhalation valve should not be used in the community to limit SARS-CoV-2 Diffusion. Infect. Control Hosp. Epidemiol. 42, 369-370. https://doi.org/10.1017/ice.2020.244

Kähler, C.J., Hain, R. (2020). Fundamental protective mechanisms of face masks against droplet infections. J. Aerosol Sci 148, 105617-105617. https://doi.org/10.1016/j.jaerosci.2020.105617

Kulmala, I., Heinonen, K., Salo, S. (2021). Improving filtration efficacy of medical face masks. Aerosol Air Qual. Res. 21, 210043. https://doi.org/10.4209/aaqr.210043 
Lee, B.U. (2020). Minimum sizes of respiratory particles carrying SARS-CoV-2 and the possibility of aerosol generation. Int. J. Environ. Res. Public Health 17, 6960. https://doi.org/10.3390/ijerp h17196960

Lee, B.U. (2021). Why does the SARS-CoV-2 Delta VOC spread so rapidly? Universal conditions for the rapid spread of respiratory viruses, minimum viral loads for viral aerosol generation, effects of vaccination on viral aerosol generation, and viral aerosol clouds. Int. J. Environ. Res. Public Health 18, 9804. https://doi.org/10.3390/ijerph18189804

Leung, N.H.L. (2021). Transmissibility and transmission of respiratory viruses. Nat. Rev. Microbiol. 19, 528-545. https://doi.org/10.1038/s41579-021-00535-6

Licina, A., Silvers, A., Stuart, R.L. (2020). Use of powered air-purifying respirator (PAPR) by healthcare workers for preventing highly infectious viral diseases-A systematic review of evidence. Syst. Rev. 9, 173. https://doi.org/10.1186/s13643-020-01431-5

Martinelli, L., Kopilaš, V., Vidmar, M., Heavin, C., Machado, H., Todorović, Z., Buzas, N., Pot, M., Prainsack, B., Gajović, S. (2021). Face masks during the COVID-19 Pandemic: A simple protection tool with many meanings. Front. Public Health 8, 606635. https://doi.org/10.3389/fpubh.2020. 606635

Milton, D.K., Fabian, M.P., Cowling, B.J., Grantham, M.L., McDevitt, J.J. (2013). Influenza virus aerosols in human exhaled breath: Particle size, culturability, and effect of surgical masks. PLoS Pathog. 9, e1003205. https://doi.org/10.1371/journal.ppat.1003205

Mueller, A.V., Eden, M.J., Oakes, J.M., Bellini, C., Fernandez, L.A. (2020). Quantitative method for comparative assessment of particle removal efficiency of fabric masks as alternatives to standard surgical masks for PPE. Matter 3, 950-962. https://doi.org/10.1016/j.matt.2020.07.006

Nelson, T.J., Colton, C.E. (2000). The effect of inhalation resistance on facepiece leakage. Am. Ind. Hyg. Assoc. J. 61, 102-105. https://doi.org/10.1080/15298660008984522

National Institute for Occupational Safety and Health (NIOSH) (2019). Determination of Particulate Filter Efficiency Level for N95 Series Filters against Solid Particulates for Non-Powered, AirPurifying Respirators Standard Test Procedure (STP). https://wwwn.cdc.gov/PPEInfo/Standard s/Info/TEBAPRSTP0059 (accessed28 December 2021).

Noti, J.D., Lindsley, W.G., Blachere, F.M., Cao, G., Kashon, M.L., Thewlis, R.E., McMillen, C.M., King, W.P., Szalajda, J.V., Beezhold, D.H. (2012). Detection of infectious influenza virus in cough aerosols generated in a simulated patient examination Room. Clin. Infect. Dis. 54, 1569-1577. https://doi.org/10.1093/cid/cis237

Oberg, T., Brosseau, L.M. (2008). Surgical mask filter and fit performance. Am. J. Infect. Control 36, 276-282. https://doi.org/10.1016/j.ajic.2007.07.008

Pan, J., Harb, C., Leng, W., Marr, L.C. (2021). Inward and outward effectiveness of cloth masks, a surgical mask, and a face shield. Aerosol Sci. Technol. 55, 718-733. https://doi.org/10.1080/02 786826.2021.1890687

Peacock, T.P., Brown, J.C., Zhou, J., Thakur, N., Newman, J., Kugathasan, R., Sukhova, K., Kaforou, M., Bailey, D., Barclay, W.S. (2022). The SARS-CoV-2 variant, omicron, shows rapid replication in human primary nasal epithelial cultures and efficiently uses the endosomal route of entry. bioRxiv 2021.2012.2031.474653. https://doi.org/10.1101/2021.12.31.474653

Rahimi, Z., Shirali, G.A., Araban, M., Mohammadi, M.J., Cheraghian, B. (2021). Mask use among pedestrians during the COVID-19 pandemic in Southwest Iran: An observational study on 10,440 people. BMC Public Health 21, 133. https://doi.org/10.1186/s12889-020-10152-2

Riedikera, M., Briceno-Ayalab, L., Ichiharac, G., Albanid, D., Poffete, D., Tsaia, D.H., Ifff, S., Monnf, C. (2022). Higher viral load and infectivity increase risk of aerosol transmission for delta and omicron variants of SARS-CoV-2. Swiss Med. Wkly. 152, w30133. https://doi.org/10.4414/smw. 2022.w30133

Rothamer, D.A., Sanders, S., Reindl, D., Bertram, T.H. (2021). Strategies to minimize SARS-CoV-2 transmission in classroom settings: Combined impacts of ventilation and mask effective filtration efficiency. Sci. Technol. Built Environ. 27, 1181-1203. https://doi.org/10.1080/23744 731.2021.1944665

Sankhyan, S., Heinselman, K.N., Ciesielski, P.N., Barnes, T., Himmel, M.E., Teed, H., Patel, S., Vance, M.E. (2021). Filtration performance of layering masks and face coverings and the reusability of cotton masks after repeated washing and drying. Aerosol Air Qual. Res. 21, 210117. https://doi.org/10.4209/aaqr.210117 
Scheuch, G. (2020). Breathing is enough: For the spread of influenza virus and SARS-CoV-2 by breathing only. J. Aerosol Med. Pulm. Drug Deliv. 33, 230-234. https://doi.org/10.1089/jamp.2 020.1616

Smither, S.J., Eastaugh, L.S., Findlay, J.S., Lever, M.S. (2020). Experimental aerosol survival of SARSCoV-2 in artificial saliva and tissue culture media at medium and high humidity. Emerg. Microbes Infect. 9, 1415-1417. https://doi.org/10.1080/22221751.2020.1777906

Su, W.C., Lee, J., Xi, J., Zhang, K. (2022). Investigation of mask efficiency for loose-fitting masks against ultrafine particles and effect on airway deposition efficiency. Aerosol Air Qual. Res. 22, 210228. https://doi.org/10.4209/aaqr.210228

Teyssou, E., Delagrèverie, H., Visseaux, B., Lambert-Niclot, S., Brichler, S., Ferre, V., Marot, S., Jary, A., Todesco, E., Schnuriger, A., Ghidaoui, E., Abdi, B., Akhavan, S., Houhou-Fidouh, N., Charpentier, C., Morand-Joubert, L., Boutolleau, D., Descamps, D., Calvez, V., Marcelin, A.G., Soulie, C. (2021). The delta SARS-CoV-2 variant has a higher viral load than the beta and the historical variants in nasopharyngeal samples from newly diagnosed COVID-19 patients. J. Infect. 83, e1-e3. https://doi.org/10.1016/j.jinf.2021.08.027

van Doremalen, N., Bushmaker, T., Morris, D.H., Holbrook, M.G., Gamble, A., Williamson, B.N., Tamin, A., Harcourt, J.L., Thornburg, N.J., Gerber, S.I., Lloyd-Smith, J.O., de Wit, E., Munster, V.J. (2020). Aerosol and surface stability of SARS-CoV-2 as compared with SARS-CoV-1. N. Engl. J. Med. 382, 1564-1567. https://doi.org/10.1056/NEJMc2004973

World Health Organization (WHO) (2020). Coronavirus Disease (COVID-19): Masks, https://www.who.int/emergencies/diseases/novel-coronavirus-2019/question-and-answershub/q-a-detail/coronavirus-disease-covid-19-masks (accessed: 26 July 2021).

Zhao, X., Li, X., Chai, Z., Song, H., Kang, J. (2021). Overview of the application of powered intelligent air-purifying respirator in the health field. 2021 IEEE 3rd International Conference on Civil Aviation Safety and Information Technology, IEEE, pp. 555-562. https://doi.org/10.110 9/ICCASIT53235.2021.9633740

Zhou, Y., Cheng, Y.S. (2017). Evaluation of N95 filtering facepiece respirators challenged with engineered nanoparticles. Aerosol Air Qual. Res. 16, 212-220. https://doi.org/10.4209/aaqr.20 15.06.0399 